\title{
Alkaline and alkaline-earth cyanoacetylides: A combined theoretical and rotational spectroscopic investigation
}

Cite as: J. Chem. Phys. 151, 054312 (2019); https://doi.org/10.1063/1.5110670

Submitted: 20 May 2019 . Accepted: 05 July 2019 . Published Online: 07 August 2019

Carlos Cabezas (D), Carmen Barrientos (D), Antonio Largo, Jean-Claude Guillemin (D), José Cernicharo (iD), and José L. Alonso (i)

\section{ARTICLES YOU MAY BE INTERESTED IN}

Electronic spectroscopy of carbon chains $\left(C_{2 n+1}, n=7-10\right)$ of astrophysical importance. I. Quantum chemistry

The Journal of Chemical Physics 151, 054303 (2019); https://doi.org/10.1063/1.5108725

Electronic spectroscopy of carbon chains $\left(C_{2 n+7}, n=7-10\right)$ of astrophysical importance. II. Quantum dynamics

The Journal of Chemical Physics 151, 054304 (2019); https://doi.org/10.1063/1.5108726

Sub-nanosecond secondary geminate recombination in mercury halides $\mathrm{HgX}_{2}(\mathrm{X}=\mathrm{I}, \mathrm{Br})$ investigated by time-resolved x-ray scattering

The Journal of Chemical Physics 151, 054310 (2019); https://doi.org/10.1063/1.5096422

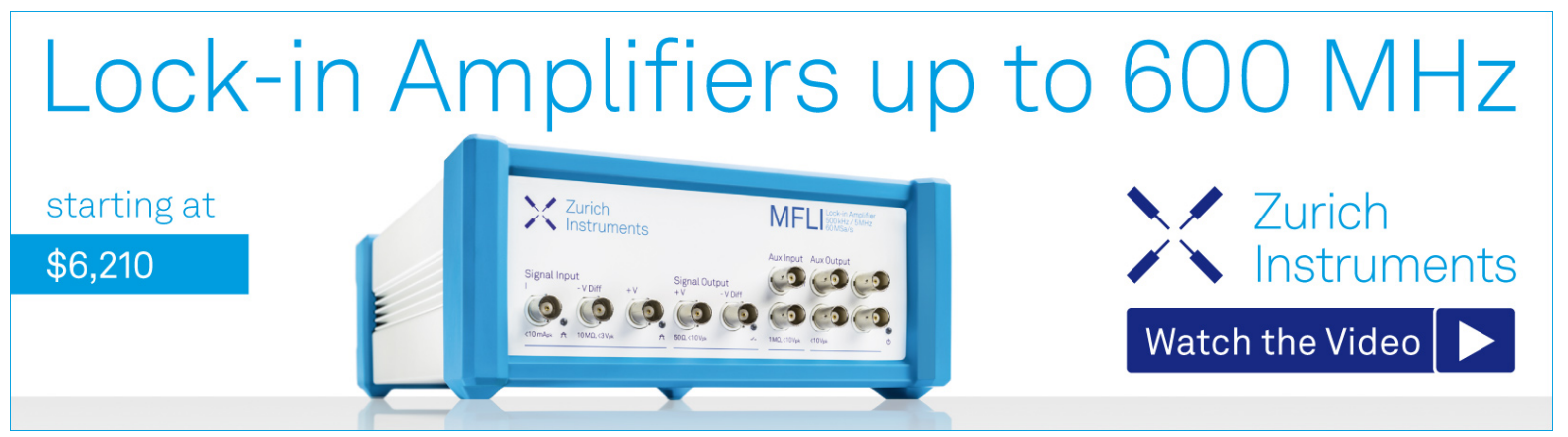

J. Chem. Phys. 151, 054312 (2019); https://doi.org/10.1063/1.5110670 


\title{
Alkaline and alkaline-earth cyanoacetylides: A combined theoretical and rotational spectroscopic investigation
}

\author{
Cite as: J. Chem. Phys. 151, 054312 (2019); doi: 10.1063/1.51 10670 \\ Submitted: 20 May 2019 Accepted: 5 July 2019 • \\ Published Online: 7 August 2019
}

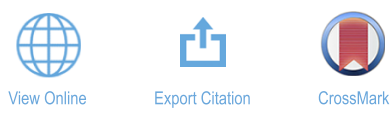

Carlos Cabezas, ${ }^{1, a)}$ (D) Carmen Barrientos, ${ }^{2}$ (D) Antonio Largo,, ${ }^{2, b)}$ Jean-Claude Guillemin,, (D) José Cernicharo, and José L. Alonso

\begin{abstract}
AFFILIATIONS
'Grupo de Espectroscopia Molecular (GEM), Edificio Quifima, Laboratorios de Espectroscopia y Bioespectroscopia, Unidad Asociada CSIC, Parque Científico Uva, Universidad de Valladolid, Paseo de Belén 5, 47011 Valladolid, Spain

${ }^{2}$ Departamento de Química Física y Química Inorgánica, Facultad de Ciencias, Universidad de Valladolid, Campus Miguel Delibes, Paseo de Belén 7, 47011 Valladolid, Spain

${ }^{3}$ Univ. Rennes, Ecole Nationale Supérieure de Chimie de Rennes, CNRS, ISCR - UMR6226, F-35000 Rennes, France ${ }^{4}$ Instituto de Física Fundamental (IFF, CSIC), Group of Molecular Astrophysics, C/Serrano 123, 28006 Madrid, Spain
\end{abstract}

\author{
a) Present address: Instituto de Física Fundamental (IFF, CSIC). Group of Molecular Astrophysics, C/Serrano 123, \\ 28006 Madrid, Spain. \\ ${ }^{b)}$ Authors to whom correspondence should be addressed: alargo@qf.uva.es and jlalonso@gf.uva.es
}

\begin{abstract}
The metallic cyanoacetylides $\mathrm{LiC}_{3} \mathrm{~N}, \mathrm{NaC}_{3} \mathrm{~N}, \mathrm{MgC}_{3} \mathrm{~N}$, and $\mathrm{CaC}_{3} \mathrm{~N}$ have been investigated by combined spectroscopy measurements and theoretical calculations. The theoretical calculations predict for the four species that the linear isomer with the formula $\mathrm{MCCCN}(\mathrm{M}=\mathrm{Li}$, Na, $\mathrm{Mg}$, and $\mathrm{Ca}$ ) is the most stable one. We used laser ablation molecular beam Fourier transform microwave (FTMW) spectroscopy to synthesize these species by the reaction of metal vapors, produced by laser ablation, and 3-bromo-2-propynenitrile (BrCCCN). Pure rotational spectra were observed by FTMW spectroscopy in the $2-18 \mathrm{GHz}$ frequency region only for LiCCCN and NaCCCN, while no spectral signatures for MgCCCN and CaCCCN could be detected. Finally, we have searched for LiCCCN and NaCCCN species toward the carbon-rich evolved star IRC +10216 , but only upper limits to their abundances have been obtained.
\end{abstract}

Published under license by AIP Publishing. https://doi.org/10.1063/1.5110670

\section{INTRODUCTION}

Several metallic cyanoacetylides have been synthesized in the gas phase in recent years. Endo and co-workers ${ }^{1}$ obtained SiCCCN in a supersonic jet by a pulsed electric discharge in a gas mixture containing $\mathrm{SiCl}_{4}$ and $\mathrm{HC}_{3} \mathrm{~N}$ diluted in Ar. They carried out a subsequent structural characterization through Fourier transform microwave (FTMW) spectroscopy. On the other hand, AlCCCN, ${ }^{2} \mathrm{CuCCCN}$, $\mathrm{AgCCCN}$, and $\mathrm{AuCCCN}^{3}$ were generated and structurally characterized in our laboratory through the laser ablation molecular beam FTMW spectrometer. These metal cyanoacetylides were obtained using 3-bromo-2-propynenitrile (BrCCCN) as the precursor. In all cases, only the MCCCN connectivity (M denoting the corresponding metal) was observed. The assignment was supported by theoretical studies which predict that MCCCN is the most stable isomer in all cases.

Metallic cyanoacetylides are interesting compounds from different points of view. They offer the possibility of studying the metal-carbon interaction and comparing it with the metal-carbon bonding in related compounds. Of paramount relevance is the metal-carbon bonding in the analog cyanides, $\mathrm{MCN}$, and their competition with the corresponding isocyanides, MNC. The MCN connectivity has been shown experimentally to be preferred for different transition metals, ${ }^{4-9}$ such as $\mathrm{Cr}, \mathrm{Co}, \mathrm{Ni}, \mathrm{Cu}$, and $\mathrm{Zn}$. This observation is in agreement with the theoretical predictions ${ }^{10,11}$ for these metals. A peculiar case is iron, for which both isomers, $\mathrm{FeCN}$ and FeNC, have been experimentally observed, ${ }^{12-14}$ with the cyanide form being more stable. Theoretical studies predict a 
different ground state depending on the level of theory employed, and the iron cyanide/isocyanide competition still remains a challenge for theoretical methods. ${ }^{15}$ Concerning main-group metals, $\mathrm{Mg}$ and $\mathrm{Al}$ favor the isocyanide isomer, ${ }^{15,16}$ whereas for silicon, the SiCN isomer is found to be lower in energy. ${ }^{17}$ Theoretical predictions are also in agreement with these observations. ${ }^{18,19}$ The quasi-isotropic charge distribution of the cyanide ligand leads to a polytopic behavior for alkaline metals, ${ }^{20}$ giving rise to T-shaped structures. ${ }^{21-23}$ It would be interesting to analyze the nature of the interaction of alkaline and alkaline-earth metals with more complex carbon-nitrogen compounds.

Several related molecules, containing different metals, have been already identified in the interstellar medium. Of particular importance is the family of cyanides/isocyanides. So far, the list of interstellar molecules includes $\mathrm{NaCN},{ }^{24} \mathrm{KCN},{ }^{25} \mathrm{MgNC},{ }^{15} \mathrm{MgCN},{ }^{26}$ HMgNC, ${ }^{27}$ AlNC, ${ }^{16} \mathrm{SiCN},{ }^{17} \mathrm{SiNC},{ }^{28}$ and $\mathrm{FeCN} .{ }^{29}$ In addition, several cyanopolyynes, ranging from $\mathrm{HC}_{3} \mathrm{~N}$ to $\mathrm{HC}_{9} \mathrm{~N}$, have also been detected in space. ${ }^{30}$ It is then feasible that, in analogy with the HCN parent molecule, substitution of the hydrogen atom by a metal could give rise to a family of carbon chains containing a nitrogen atom and a metal. The compounds with the general formula $\mathrm{MC}_{3} \mathrm{~N}$ would be the simplest among them.

Building on the success of our previous studies on metal cyanoacetylides, ${ }^{2,3}$ we have applied the same experimental approach to generate and characterize the metallic cyanoacetylides with the general formula $\mathrm{MC}_{3} \mathrm{~N}(\mathrm{M}=\mathrm{Li}, \mathrm{Na}, \mathrm{Mg}$, and $\mathrm{Ca})$. In addition to the experimental spectroscopic characterization work, we have carried out high-level $a b$ initio quantum chemical calculations to investigate the geometries, stabilities, and spectroscopic properties of these molecules. As shown below, Li- and Na-cyanoacetylides could be generated and assigned through their rotational spectra but several experiments to observe $\mathrm{Mg}$ - and $\mathrm{Ca}$-species were fruitless. This abnormal spectroscopic behavior for $\mathrm{Mg}$ - and $\mathrm{Ca}$-cyanoacetylides will be discussed.

\section{METHODS}

\section{A. Computational methods}

We have carried out explorations of potential energy surfaces for $\mathrm{MC}_{3} \mathrm{~N}$ compounds to characterize the relevant species for an experimental search. We consider the cyanoacetylides of $\mathrm{Li}$ and $\mathrm{Na}$ as representative alkaline metals while explorations for $\mathrm{MgC}_{3} \mathrm{~N}$ and $\mathrm{CaC}_{3} \mathrm{~N}$ were carried out as well.

Geometry optimizations were performed at the second-order Møller-Plesset (MP2) level of theory with Dunning's correlated consistent triple-zeta basis sets augmented with diffuse and polarization functions, usually denoted as aug-cc-pVTZ. ${ }^{31,32}$ Subsequent harmonic vibrational calculations at the MP2/aug-cc-pVTZ level were carried out for all stationary points obtained in the explorations in order to confirm that they correspond to true minima. The electronic energy was further refined carrying out $\operatorname{CCSD}(\mathrm{T})$ (coupled cluster with singles and doubles and a perturbative inclusion of triple excitations) calculations ${ }^{33}$ with the aug-cc-pVTZ basis set on the MP2 geometries. In all correlated calculations [MP2, $\operatorname{CCSD}(\mathrm{T})]$, the $1 \mathrm{~s}$ orbitals of carbon and nitrogen were kept frozen. However, for alkaline and alkaline-earth metals, it could be necessary to maintain the $\mathrm{n}-1$ orbitals active ( $\mathrm{n}$ being the largest principal quantum number of the occupied orbitals in the ground state). Thus, for alkaline and alkaline-earth metals, only the $\mathrm{n}-2$ orbitals were excluded from the active space in correlated calculations. This means that for $\mathrm{Li}$, all electrons were included in the calculations, whereas for $\mathrm{Na}$ and $\mathrm{Mg}$, just the $1 \mathrm{~s}$ orbital was kept frozen. In the case of $\mathrm{Ca}, 1 \mathrm{~s}, 2 \mathrm{~s}$, and $2 \mathrm{p}$ orbitals were considered as inactive orbitals in the correlated calculations.

Coupled cluster (CC) theory provides a systematic approach for the treatment of electron-correlation in molecular systems. However, CC calculations are, in general, extremely costly and cannot be used together with a sufficiently large basis set. Thus, to reach accurate predictions of molecular properties, it is necessary to introduce additional approximations that are based on the additivity of electron correlation and basis-set effects. In order to aid in the assignment of the rotational spectra, reliable predictions for the rotational constants are required. For this purpose, a composite procedure has been applied. Gauss et al. ${ }^{34,35}$ developed composite schemes at the coupled-cluster level, whereas Barone et al. ${ }^{36}$ employed a more affordable version of the method, in terms of computational demands, involving geometry optimizations at the MP2 level. Basically, the method of Barone et al. ${ }^{36}$ is based on the extrapolation to the CBS limit of MP2 geometrical parameters, including corrections for core-valence correlation, inclusion of diffuse functions, and the effect of $\operatorname{CCSD}(\mathrm{T})$ corrections. In order to obtain an estimate of $\mathrm{B}_{0}$ rotational constants, vibration-rotation interaction constants were estimated using second-order perturbation theory at the MP2/augcc-pVTZ level. Quadrupole coupling constants were also estimated using the CCSD/aug-cc-pVTZ electronic density. In order to aid in a possible experimental detection by IR spectroscopy, anharmonic vibrational frequencies and IR intensities have been predicted for the most stable isomer in each case. It should be noted in this point that the composite approach used in this work allows for the calculation of spectroscopic properties with an overall accuracy of about $20 \mathrm{MHz}$ for rotational constants. Both Gaussian $09^{37}$ and CFOUR ${ }^{38}$ program packages were employed in this study.

\section{B. LA-MB-FTMW spectroscopy}

All the experiments to observe the rotational spectra of Li-, Na-, Mg-, and Ca-cyanoacetylides were performed using a LA-MB-FTMW spectrometer constructed at the University of Valladolid operating in the $2-18 \mathrm{GHz}$ frequency range. The instrument has been described in detail elsewhere. ${ }^{39}$ Briefly, this Balle-Flygare type Fourier-transform cavity microwave spectrometer ${ }^{40}$ consists of a cylindrical stainless-steel high vacuum chamber, which contains a Fabry-Pérot resonator formed by two spherical aluminum mirrors. As previously reported, ${ }^{2,3}$ for these kinds of studies, the pulsed nozzle system has been modified by the addition of a home-made heatable reservoir extension, placed to hold liquid and/or solid compounds which can be used as precursors of metal bearing species. Metallic cyanoacetylides are generated using this device by laser ablation of pure metal rods in the throat of a pulsed supersonic expansion of $\mathrm{Ne}$ and $\mathrm{BrCCCN}$ (prepared as previously reported) ${ }^{2,3}$ as described below.

Producing a rod of an alkali metal is problematic, so we employed a different method than that used in previous studies. In a $40 \mathrm{~mm}$ stainless steel rod with a diameter of $6 \mathrm{~mm}$, we machined a $30 \mathrm{~mm}$ notch, with a diameter $1.5 \mathrm{~mm}$ smaller than the rod itself. 
Since $\mathrm{Li}$ and $\mathrm{Na}$ are malleable metals, a piece of the solid metal was pressed into the notch and for better adhesion the rod was then introduced into an in-house designed cast and pressed with a standard hydraulic bench press. Before being inserted in the ablation housing, the alkali metal-coated portion of the rod was submerged in kerosene to avoid the oxidation or inflammation of the alkali metal. In contrast, for $\mathrm{Mg}$ and $\mathrm{Ca}$, standard rods of pure metals were used.

The $\mathrm{MC}_{3} \mathrm{~N}$ species were produced by the chemical reaction between the vapor metal, which was ablated using a picosecond Nd:YAG-laser pulse $\left(\lambda=355 \mathrm{~nm}\right.$ and $10 \mathrm{~mJ}$ pulse $\left.^{-1}\right)$, and the precursor BrCCCN (heated at $\sim 65^{\circ} \mathrm{C}$ ). A motorized micrometer is used to simultaneously rotate and translate the sample rod at each laser pulse, so the laser hits a different point of the sample surface in successive pulses, minimizing the problem of shot-to-shot fluctuation in the amount of the desorbed material. All the resulting products generated in the reaction are supersonically expanded and rapidly cooled to a rotational temperature of $\sim 2 \mathrm{~K}$ between the two mirrors of the Fabry-Pérot resonator and then probed by Fourier-transform microwave spectroscopy. Typically, 100-200 pulses were accumulated to achieve an adequate signal-to-noise ratio.

\section{RESULTS}

\section{A. Alkaline metals}

We searched for different possible minima on the $\mathrm{XC}_{3} \mathrm{~N}$ potential surface $(\mathrm{X}=\mathrm{Li}, \mathrm{Na})$. We consider cyclic or T-shaped structures, resulting from $\pi$ interactions, but in all cases, they eventually evolve to linear structures. We characterized four different linear isomers, differing in the position of the nitrogen atom in the chain. Their optimized structures at the MP2/aug-cc-pVTZ level are shown in Fig. 1, whereas the corresponding relative energies at MP2 and $\operatorname{CCSD}(\mathrm{T})$ levels of theory, rotational constants, and dipole moments are given in Table I.

It can be seen in Fig. 1 that the $\mathrm{C}-\mathrm{C}$ and $\mathrm{C}-\mathrm{N}$ bond distances for the analog lithium and sodium isomers are quite similar, suggesting that no essential changes in the carbon-nitrogen chain are produced upon substitution of lithium by sodium. Only the metal-carbon/nitrogen distances are significantly different. As expected, the optimized $\mathrm{Li}-\mathrm{C}$ and $\mathrm{Li}-\mathrm{N}$ distances are considerably shorter than the corresponding $\mathrm{Na}-\mathrm{C}$ and $\mathrm{Na}-\mathrm{N}$ distances (by around $0.27-0.29 \AA$ ), reflecting both the strength of the bonds and the size of the involved alkaline atom. It is remarkable that the predicted dipole moments are very high for all isomers (from $9.49 \mathrm{D}$ to $18.61 \mathrm{D})$, reflecting the expected high ionic character of the metal- $\mathrm{C}_{3} \mathrm{~N}$ bonding. The high values of the dipole moments should favor the experimental detection of these species by rotational spectroscopy, since intense lines in the rotational spectra are expected.

According to the energy values shown in Table I, the most stable isomer is linear MCCCN. Relative energies for the other isomers are very similar to those for both $\mathrm{LiC}_{3} \mathrm{~N}$ and $\mathrm{NaC}_{3} \mathrm{~N}$. The second most stable isomer is MNCCC, with the metal bonded to the nitrogen atom but keeping the CCCN chain. The other two isomers, with the nitrogen atom in the middle position of the carbon-nitrogen chain, are less stable. We confirm that all species are true minima
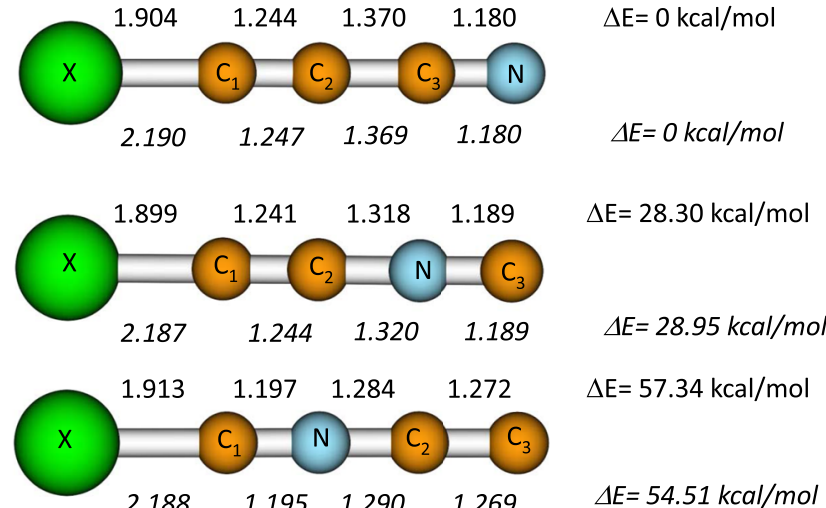

$\Delta \mathrm{E}=57.34 \mathrm{kcal} / \mathrm{mol}$

$\Delta E=54.51 \mathrm{kcal} / \mathrm{mol}$

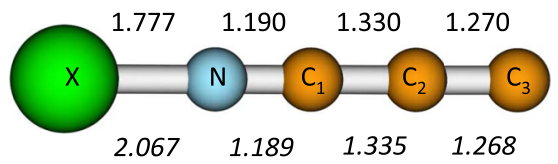

$\Delta \mathrm{E}=18.14 \mathrm{kcal} / \mathrm{mol}$

$\Delta E=17.53 \mathrm{kcal} / \mathrm{mol}$

FIG. 1. Equilibrium geometries and relative energies (ZPE corrections are included) of the equilibrium structures for the different $\mathrm{MC}_{3} \mathrm{~N}(\mathrm{M}=\mathrm{Li}, \mathrm{Na})$ isomers obtained at the MP2/aug-cc-pVTZ and the CCSD(T)/aug-cc-pVTZ//MP2/augcc-pVTZ levels, respectively. Distances are given in Ångstroms. Upper values are for $\mathrm{LiC}_{3} \mathrm{~N}$ species, whereas lower values (in Italics) correspond to $\mathrm{NaC}_{3} \mathrm{~N}$ isomers.

on the corresponding potential energy surface through computation of the vibrational frequencies. All of the studied isomers have all their frequencies real. In Table II, we provide the anharmonic vibrational frequencies at the MP2/aug-cc-pVTZ level for the most stable species, LiCCCN and NaCCCN. Most fundamental frequencies are rather close for both systems. The main difference concerns the $\mathrm{M}-\mathrm{C}_{1}$ stretching frequency, which is much higher for LiCCCN $\left(586 \mathrm{~cm}^{-1}\right)$ than for NaCCCN $\left(292 \mathrm{~cm}^{-1}\right)$, in accordance with the expected stronger metal-carbon bond for lithium. In both cases, it should give rise to a relatively strong line in the IR spectrum.

TABLE I. Relative energies $(\mathrm{kcal} / \mathrm{mol})$ of the different $\mathrm{LiC}_{3} \mathrm{~N}$ and $\mathrm{NaC}_{3} \mathrm{~N}$ species obtained at the MP2 and $\operatorname{CCSD}(T)$ levels with the aug-cc-pVTZ basis set. Zero-point vibrational energy (ZPVE) corrections are taken into account at the MP2/aug-ccpVTZ level. Equilibrium rotational constants $(\mathrm{MHz})$ and dipole moments (Debye) are estimated at the MP2/aug-cc-pVTZ level.

\begin{tabular}{lcccr}
\hline \hline & $\Delta \mathrm{E}(\mathrm{MP} 2)$ & $\Delta \mathrm{E}(\mathrm{CCSD}(\mathrm{T}))$ & $\mathrm{B}$ & $\mu$ \\
\hline LiCCCN & 0.0 & 0.0 & 2556.7 & 11.57 \\
LiCCNC & 32.18 & 28.30 & 2731.2 & 9.49 \\
LiCNCC & 58.04 & 57.34 & 2784.7 & 16.28 \\
LiNCCC & 20.07 & 18.14 & 2772.6 & 13.86 \\
& & & & \\
NaCCCN & 0.0 & 0.0 & 1330.9 & 13.60 \\
NaCCNC & 32.60 & 28.95 & 1399.8 & 11.52 \\
NaCNCC & 55.65 & 54.51 & 1444.2 & 18.61 \\
NaNCCC & 19.11 & 17.53 & 1489.1 & 16.34 \\
\hline \hline
\end{tabular}


TABLE II. Anharmonic vibrational frequencies $\left(\omega, \mathrm{cm}^{-1}\right)$ and IR intensities $(\mathrm{l}, \mathrm{km} / \mathrm{mol})$ for LiCCCN and NaCCCNevaluated at the MP2/aug-cc-pVTZ level.

\begin{tabular}{lccccr}
\hline \hline & \multicolumn{2}{c}{ LiCCCN } & & \multicolumn{2}{c}{ NaCCCN } \\
\cline { 2 - 3 } \cline { 5 - 6 } Symmetry/mode & $\omega$ & $\mathrm{I}$ & & $\omega$ & \multicolumn{1}{c}{$\mathrm{I}$} \\
\hline$\pi \mathrm{MC}_{1} \mathrm{C}_{2}$ bend & 104 & 58.00 & & 71 & 23.14 \\
$\pi \mathrm{C}_{1} \mathrm{C}_{2} \mathrm{C}_{3}$ bend & 264 & 38.53 & & 263 & 28.29 \\
$\pi \mathrm{C}_{2} \mathrm{C}_{3} \mathrm{~N}$ bend & 534 & 3.09 & & 555 & 3.54 \\
$\sigma \mathrm{M}-\mathrm{C}_{1}$ stretch & 586 & 34.18 & & 292 & 20.84 \\
$\sigma \mathrm{C}_{2}-\mathrm{C}_{3}$ stretch & 919 & 62.53 & & 894 & 26.32 \\
$\sigma \mathrm{C}_{1}-\mathrm{C}_{2}$ stretch & 1956 & 9.54 & & 1945 & 0.82 \\
$\sigma \mathrm{C}_{3}-\mathrm{N}$ stretch & 2137 & 18.14 & & 2134 & 51.01 \\
\hline \hline
\end{tabular}

More accurate predictions of the rotational constants, employing the previously mentioned composite method and vibration-rotation interactions, were carried out for the predicted global minima, LiCCCN and NaCCCN. These predictions include as well other parameters necessary to interpret the rotational spectrum such as the dipole moments and the nuclear quadrupole coupling constants. The results obtained are collected in Table III.

With the help of the predicted molecular parameters, initial experiments were devoted to search for the rotational transitions of Li-cyanoacetylide, in particular, the lines owing to the predicted global minima, LiCCCN. In this way, frequency scans around $5.0 \mathrm{GHz}$ were directed to detect spectral signatures corresponding to the $J=1-0$ rotational transition of LiCCCN, according to the transition frequencies calculated from the estimated rotational constants of Table III. A group of lines centered around $5157 \mathrm{MHz}$, showing a hyperfine structure, was finally observed. The corresponding rotational transitions $J=2-1$ and $J=3-2$ were then predicted and observed. The roughly estimated value of the rotational constants for the observed species is $B \approx 2580 \mathrm{MHz}$, in good agreement with the predicted value for the LiCCCN isomer, indicating that this species is generated in the supersonic expansion of our experiment. Additional wide frequency scans around $5.4 \mathrm{GHz}$ were done to find rotational signatures of $\mathrm{LiC}_{3} \mathrm{~N}$ isomers, but they were fruitless.

LiCCCN possesses two nuclei with quadrupole moment, ${ }^{14} \mathrm{~N}(I=1)$ and ${ }^{7} \mathrm{Li}(I=3 / 2)$. The interaction at the nuclei of these quadrupole moments with the electric field gradient created by the rest of the molecular charges causes the coupling of the nuclear spin moments to the overall rotational momentum. Hence, each rotational transition of LiCCCN carried the nuclear quadrupole hyperfine pattern expected for the presence of the ${ }^{7} \mathrm{Li}$ nucleus and the additional quadrupolar effect of the ${ }^{14} \mathrm{~N}$ nucleus giving rise to a hyperfine pattern like the one shown in Fig. 2 for the $J=1-0$ rotational transition. A total of 58 hyperfine components (Table S1 of the supplementary material) were analyzed ${ }^{41}$ using a ${ }^{1} \Sigma$ Hamiltonian of the following form: ${ }^{42} H=H_{R}+H_{Q}(\mathrm{Li})+H_{Q}(\mathrm{~N})$, where $H_{R}$ contains rotational and centrifugal distortion parameters, while $H_{Q}(\mathrm{Li})$ and $H_{Q}(\mathrm{~N})$ are the quadrupole coupling interactions for ${ }^{7} \mathrm{Li}$ and ${ }^{14} \mathrm{~N}$ nuclei, respectively. The energy levels involved in each transition are labeled with the quantum numbers $J, F_{1}$, and $F$, where $F_{1}=J+I_{\mathrm{Li}}$ and $F=F_{1}+I_{\mathrm{N}}$. The experimental values for the rotational parameters $B$ and $D$, and the electric quadrupole coupling constant $e Q q$ for the ${ }^{7} \mathrm{Li}$ and ${ }^{14} \mathrm{~N}$ nuclei were derived from the analysis and are listed in Table III, along with the theoretical ones. The standard deviation obtained for the fit is $0.7 \mathrm{kHz}$. As can be seen, confirmation of the observed species as the linear LiCCCN isomer resides in the excellent agreement between the experimental and theoretical values of the rotational and ${ }^{7} \mathrm{Li}$ and ${ }^{14} \mathrm{~N}$ nuclear quadrupole coupling constants.

In the case of $\mathrm{NaC}_{3} \mathrm{~N}$, frequency scans were conducted to search for the $J=2-1$ transition of the global minimum NaCCCN in the frequency region around $5.2 \mathrm{GHz}$. One cluster of lines showing a very congested hyperfine structure was detected centered at $5284 \mathrm{MHz}$ (see Fig. 3). In addition, another five rotational transitions at $2.6,7.9,10.5,13.2$, and $15.8 \mathrm{GHz}$ corresponding to $J=1-0, J=3-2$, $J=4-3, J=5-4$, and $J=6-5$, respectively, were measured. As in the case of LiCCCN, the experimental value of the rotational constant for the observed isomer $(B \approx 1320 \mathrm{MHz})$ clearly points to the observation of the $\mathrm{NaCCCN}$ isomer.

TABLE III. Theoretical and experimental spectroscopic constants for the LiCCCN and NaCCCN isomers.

\begin{tabular}{lccccc}
\hline \hline & \multicolumn{2}{c}{ LiCCCN } & & \multicolumn{2}{c}{ NaCCCN } \\
\cline { 2 - 3 } \cline { 5 - 6 } Parameter & Theoretical & Experimental & & Theoretical & Experimental \\
\hline $\mathrm{B}(\mathrm{MHz})$ & $2581.6^{\mathrm{a}}$ & $2579.348998(74)^{\mathrm{b}}$ & & $1343.3^{\mathrm{a}}$ & $1321.094334(28)$ \\
$\mathrm{D}(\mathrm{kHz})$ & $0.1931^{\mathrm{c}}$ & $0.2350(49)$ & & $0.0922^{\mathrm{c}}$ & $0.1011(7)$ \\
$\mathrm{eQq}(\mathrm{Li} / \mathrm{Na})(\mathrm{MHz})$ & $0.462^{\mathrm{d}}$ & $0.3603(11)$ & & $-6.808^{\mathrm{d}}$ & $-7.0497(7)$ \\
$\mathrm{eQq}(\mathrm{N})(\mathrm{MHz})$ & $-4.064^{\mathrm{d}}$ & $-3.9695(4)$ & & $-3.9748^{\mathrm{d}}$ & $-3.8761(5)$ \\
$\mathrm{Rms}^{\mathrm{e}}(\mathrm{kHz})$ & & 0.7 & & 0.9 \\
$\mathrm{~N}^{\mathrm{f}}$ & & 58 & & 122 \\
\hline
\end{tabular}

${ }^{a}$ Composite method including vibration-rotation interaction at the MP2/aug-cc-pVTZ level.

${ }^{\mathrm{b}}$ Values in parentheses denote $1 \sigma$ errors, applied to the last digit.

${ }^{c}$ MP2/aug-cc-pVTZ level.

${ }^{\mathrm{d} C C S D / a u g-c c-p V T Z}$ level.

${ }^{\mathrm{e}}$ Root mean square of the fit.

${ }^{\mathrm{f}}$ Number of hyperfine components included in the fit. 


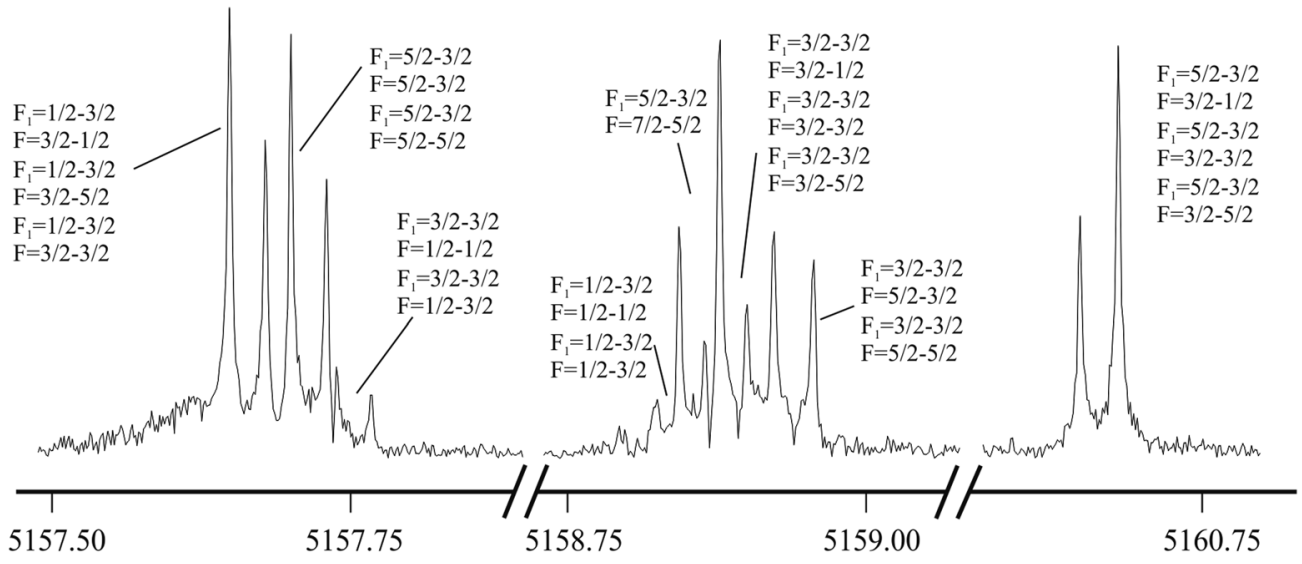

Frequency $(\mathrm{MHz})$

FIG. 2. Spectrum of a section of the $J=1-0$ rotational transition of LiCCCN near $5.2 \mathrm{GHz}$ showing the multiple hyperfine components arising from both ${ }^{7} \mathrm{Li}(I=3 / 2)$ and ${ }^{14} \mathrm{~N}(\mathrm{I}=1)$ nuclei. The coaxial arrangement of the adiabatic expansion and the resonator axis produces an instrumental Doppler doubling. The resonances frequencies are calculated as the average of the two Doppler components. Each hyperfine component is labeled with the corresponding values of $F_{1}^{\prime}, F^{\prime} \leftarrow F_{1}^{\prime \prime}, F^{\prime \prime}$ quantum numbers.

$\mathrm{NaCCCN}$ as LiCCCN possesses two nuclei with quadrupole moment. With ${ }^{23} \mathrm{Na}(I=3 / 2)$ and ${ }^{14} \mathrm{~N}(I=1)$ nuclei, each rotational transition of $\mathrm{NaCCCN}$ presents a very complex hyperfine pattern as shown in Fig. 3 for the $J=2-1$ rotational transition. A ${ }^{1} \sum$ Hamiltonian with the following form ${ }^{42} H=H_{R}+H_{Q}(\mathrm{Na})+H_{Q}(\mathrm{~N})$ was used to fit 122 hyperfine components, and the analysis rendered the rotational parameters $B$ and $D$ and the electric nuclear quadrupole coupling constants for the ${ }^{23} \mathrm{Na}$ and ${ }^{14} \mathrm{~N}$ nuclei, which are listed in Table III. Again, the good agreement between the experimental and predicted values confirms the observation of the $\mathrm{NaCCCN}$ isomer.
No other lines attributable to further isomers were observed despite the wide frequency regions scanned.

\section{B. Alkaline-earth metals}

In the same way done for $\mathrm{Li}$ and $\mathrm{Na}$, we searched for different possible minima on the $\mathrm{Mg}$ and $\mathrm{CaC}_{3} \mathrm{~N}$ potential surfaces, considering cyclic or T-shaped structures as well as linear structures. In this case, we found two three-member-cyclic structures with $\mathrm{Mg} / \mathrm{Ca}$ in the middle of the chain. Thus, the optimization ended up with

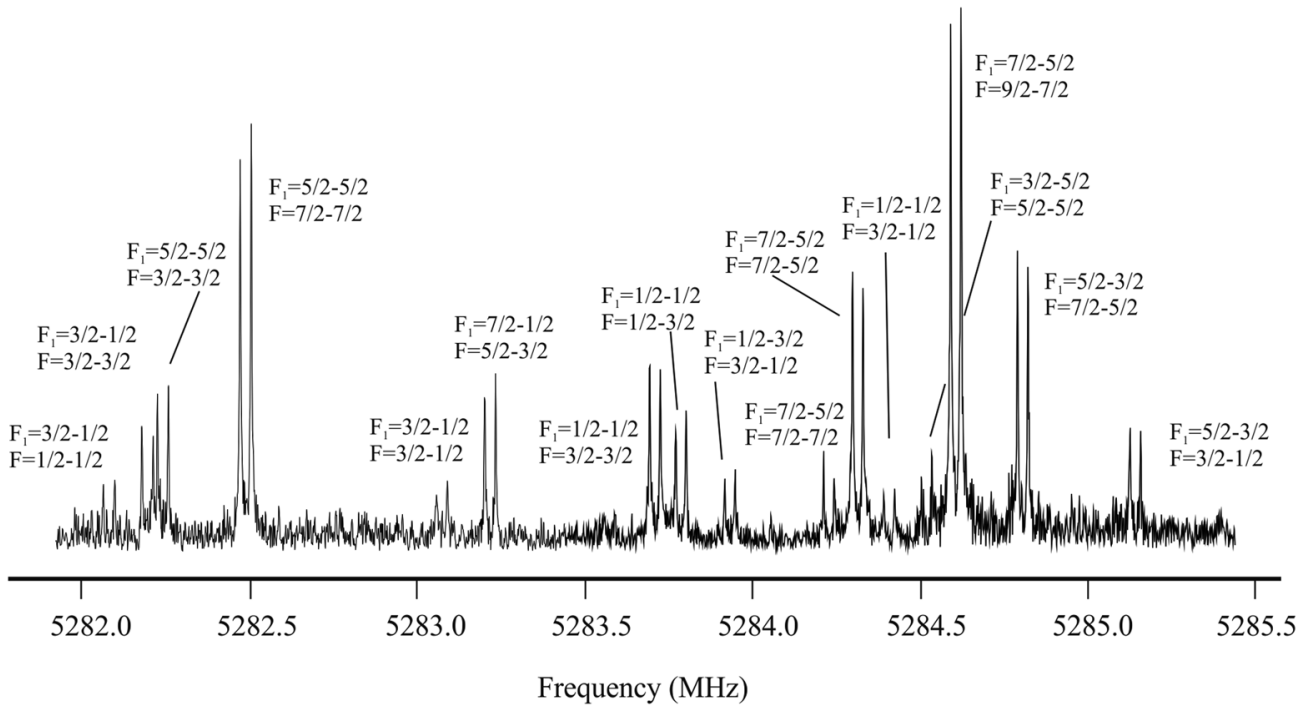

FIG. 3. Central section of the $J=2-1$ rotational transition of $\mathrm{NaCCCN}$. The nuclear quadrupole coupling hyperfine structure arising from both ${ }^{23} \mathrm{Na}(I=3 / 2)$ and ${ }^{14} \mathrm{~N}(I=1)$ nuclei is clearly resolved. Each hyperfine component is labeled with the corresponding values of $F_{1}{ }^{\prime}, F^{\prime} \leftarrow F_{1}{ }^{\prime \prime}, F^{\prime \prime}$ quantum numbers. 

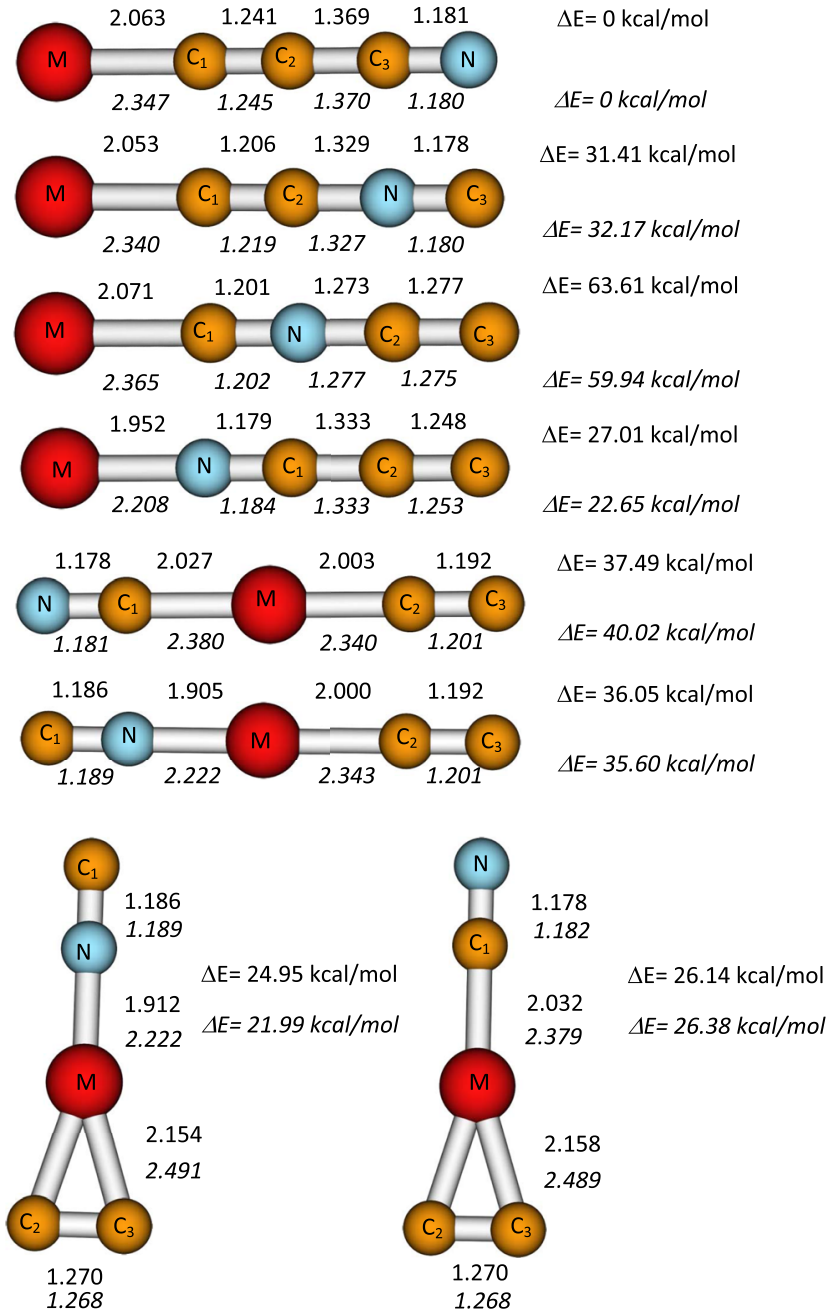

FIG. 4. Equilibrium geometries and relative energies (ZPE corrections are included) for the different $\mathrm{MC}_{3} \mathrm{~N}(\mathrm{M}=\mathrm{Mg}, \mathrm{Ca}$ ) isomers obtained at the MP2/augcc-pVTZ and the CCSD(T)/aug-cc-pVTZ//MP2/aug-cc-pVTZ levels, respectively. Distances are given in Ångstroms. Upper values are for $\mathrm{MgC}_{3} \mathrm{~N}$ species, whereas lower values (in italics) correspond to $\mathrm{CaC}_{3} \mathrm{~N}$ isomers.

either $\mathrm{CN}-\mathrm{M}\left(\mathrm{C}_{2}\right)$ or $\mathrm{NC}-\mathrm{M}\left(\mathrm{C}_{2}\right)(\mathrm{M}=\mathrm{Mg}, \mathrm{Ca})$. These two structures have an $\mathrm{MC}_{2}$ triangle subunit bonded to $\mathrm{CN}$ through either the nitrogen or the carbon atom, respectively. All the optimized structures at the MP2/aug-cc-pVTZ level are shown in Fig. 4, whereas the corresponding relative energies at MP2 and $\operatorname{CCSD}(\mathrm{T})$ levels of theory, rotational constants, and dipole moments are given in Table IV. We confirm that all species are true minima on the corresponding potential energy surface through the computation of the vibrational frequencies. All of the studied isomers have all their frequencies real. In Table $\mathrm{V}$, we provide the anharmonic vibrational frequencies at the MP2/aug-cc-pVTZ level for the most stable species, MgCCCN and $\mathrm{CaCCCN}$.

As can be seen in Fig. 4, Mg- and $\mathrm{Ca}-\mathrm{C}_{3} \mathrm{~N}$ follow the same trends found for lithium and sodium isomers and the $\mathrm{C}-\mathrm{C}$ and $\mathrm{C}-\mathrm{N}$ bond distances for the analog isomers are quite similar, suggesting
TABLE IV. Relative energies (kcal/mol) of the different $\mathrm{MgC}_{3} \mathrm{~N}$ and $\mathrm{CaC}_{3} \mathrm{~N}$ species obtained at the MP2 and CCSD(T) levels with the aug-cc-pVTZ basis set. Zero-point vibrational energy (ZPVE) corrections are taken into account at the MP2/aug-ccpVTZ level. Equilibrium rotational constants ( $\mathrm{MHz}$ ) and dipole moments (Debye) are estimated at the MP2/aug-cc-pVTZ level.

\begin{tabular}{lcccccr}
\hline \hline & $\begin{array}{c}\Delta \mathrm{E} \\
(\mathrm{MP} 2)\end{array}$ & $\begin{array}{c}\Delta \mathrm{E} \\
(\mathrm{CCSD}(\mathrm{T}))\end{array}$ & $\mathrm{A}$ & $\mathrm{B}$ & $\mathrm{C}$ & $\mu$ \\
\hline $\mathrm{MgCCCN}$ & 0.0 & 0.0 & & 1366.0 & & 6.26 \\
$\mathrm{MgCCNC}$ & 36.98 & 31.41 & & 1469.1 & & 5.20 \\
$\mathrm{MgCNCC}$ & 63.48 & 63.61 & & 1479.2 & & 10.36 \\
$\mathrm{MgNCCC}$ & 30.01 & 27.01 & & 1536.1 & & 10.17 \\
$\mathrm{CCMgCN}$ & 54.41 & 37.49 & & 1391.7 & & 2.53 \\
$\mathrm{CCMgNC}$ & 55.46 & 36.05 & & 1505.4 & & 2.68 \\
$\mathrm{CNMg}\left(\mathrm{C}_{2}\right)$ & 42.65 & 24.95 & 52185.3 & 1905.9 & 1838.7 & 3.25 \\
$\mathrm{NCMg}\left(\mathrm{C}_{2}\right)$ & 41.39 & 26.14 & 52200.6 & 1739.1 & 1683.0 & 3.08 \\
& & & & & & \\
$\mathrm{CaCCCN}$ & 0.0 & 0.0 & & 967.9 & & 7.78 \\
$\mathrm{CaCCNC}$ & 37.09 & 32.17 & & 1023.2 & & 6.73 \\
$\mathrm{CaCNCC}$ & 60.11 & 59.94 & & 1038.7 & & 12.29 \\
$\mathrm{CaNCCC}$ & 25.25 & 22.65 & & 1102.8 & & 11.65 \\
$\mathrm{CCCaCN}$ & 57.47 & 40.02 & & 1096.4 & & 2.43 \\
$\mathrm{CCCaNC}^{\mathrm{a}}$ & 55.12 & 35.60 & & 1188.4 & & 2.15 \\
$\left.\mathrm{CNCa}^{\mathrm{a}} \mathrm{C}_{2}\right)$ & 40.85 & 21.99 & 52405.3 & 1461.4 & 1421.7 & 3.14 \\
$\left.\mathrm{NCCa}^{2} \mathrm{C}_{2}\right)$ & 43.09 & 26.38 & 52401.4 & 1330.8 & 1297.9 & 3.38 \\
\hline \hline
\end{tabular}

${ }^{a}$ Structures with two degenerate $\pi$ vibrational frequencies.

that no essential changes in the carbon-nitrogen chain are produced upon substitution of $\mathrm{Mg}$ by $\mathrm{Ca}$. Only the metal-carbon/nitrogen distances are significantly different.

The rotational transition frequencies of the global minima $\mathrm{MgCCCN}$ and $\mathrm{CaCCCN}$ species were predicted using the rotational and quadrupole coupling constants listed in Table VI. It has to be noted that both isomers are paramagnetic species $\left({ }^{2} \Sigma^{+}\right.$ground electronic state) and thus their rotational spectrum would show fine and hyperfine splitting. The total coupling scheme for them is that the rotational angular momentum $N$ couples with the total electron spin angular momentum $S$ to give the fine structure, $J=N+S$, which further couples with the nuclear spin angular momentum $I$ to give the hyperfine structure, $\boldsymbol{F}=\boldsymbol{J}+\boldsymbol{I}\left({ }^{14} \mathrm{~N}\right)$. Due to the total electron spin $(S=1 / 2)$ in the doublet state, every $N$ state is split into two $J$ levels,

TABLE V. Anharmonic vibrational frequencies $\left(\omega, \mathrm{cm}^{-1}\right)$ and $\mathrm{IR}$ intensities $(\mathrm{l}, \mathrm{km} / \mathrm{mol})$ for $\mathrm{MgCCCN}$ and $\mathrm{CaCCCN}$ evaluated at the MP2/aug-cc-pVTZ level.

\begin{tabular}{lcrrrr}
\hline \hline & \multicolumn{2}{c}{ MgCCCN } & & \multicolumn{2}{c}{ CaCCCN } \\
\cline { 2 - 3 } \cline { 5 - 6 } Symmetry/mode & \multicolumn{1}{c}{$\omega$} & \multicolumn{1}{c}{$\mathrm{I}$} & & \multicolumn{1}{c}{$\mathrm{I}$} \\
\hline$\pi \mathrm{MC}_{1} \mathrm{C}_{2}$ bend & 79 & 0.16 & & 62 & 0.47 \\
$\pi \mathrm{C}_{1} \mathrm{C}_{2} \mathrm{C}_{3}$ bend & 262 & 5.69 & & 243 & 6.62 \\
$\sigma \mathrm{M}-\mathrm{C}_{1}$ stretch & 401 & 70.53 & & 296 & 55.72 \\
$\pi \mathrm{C}_{2} \mathrm{C}_{3} \mathrm{~N}$ bend & 515 & 2.68 & & 486 & 3.30 \\
$\sigma \mathrm{C}_{2}-\mathrm{C}_{3}$ stretch & 928 & 54.22 & & 906 & 54.24 \\
$\sigma \mathrm{C}_{1}-\mathrm{C}_{2}$ stretch & 1936 & 9.42 & & 1940 & 11.11 \\
$\sigma \mathrm{C}_{3}-\mathrm{N}$ stretch & 2389 & 37.29 & 2177 & 24.34 \\
\hline \hline
\end{tabular}


TABLE VI. Theoretical spectroscopic constants for the MgCCCN and CaCCCN isomers.

\begin{tabular}{lcc}
\hline \hline Parameter & MgCCCN & CaCCCN \\
\hline & Theoretical & Theoretical \\
\hline $\mathrm{B}(\mathrm{MHz})$ & $1391.3^{\mathrm{a}}$ & $982.4^{\mathrm{a}}$ \\
$\mathrm{D}(\mathrm{kHz})$ & $0.0622^{\mathrm{b}}$ & $0.0922^{\mathrm{b}}$ \\
$\mathrm{eQq}(\mathrm{N})(\mathrm{MHz})$ & $-4.1106^{\mathrm{c}}$ & $-0.2992^{\mathrm{c}}$ \\
\hline \hline
\end{tabular}

${ }^{a}$ Composite method including vibration-rotation interaction at the MP2/aug-cc-pVTZ level.

${ }^{\mathrm{b}} \mathrm{MP} 2 /$ aug-cc-pVTZ level.

${ }^{c} \mathrm{CCSD} /$ aug-cc-pVTZ level.

which are further split into hyperfine levels by ${ }^{14} \mathrm{~N}$ nuclear spin $(I=1)$. In addition, each transition for MgCCCN and CaCCCN would show first-order Zeeman splitting due to the Earth's magnetic field. To avoid this effect, a set of three mutually perpendicular Helmholtz coils are used to collapse the Zeeman pattern down to the expected Doppler components.

First, we searched for the $N=2-1$ transition predicted around $5.5 \mathrm{GHz}$ using the same experimental conditions than those used for Li- and $\mathrm{Na}$-cyanoacetylides. We scanned large frequency regions (wider than $2 \mathrm{GHz}$ ) for several times increasing the number of shots per point, but we could not observe any lines attributable to MgCCCN species. We searched for the $N=1-0$ and 3-2 transitions around 2.7 and $8.2 \mathrm{GHz}$ regions, but signals were not found either. In light of this result, we predicted the rotational transition frequencies for the higher energy isomers and then searched for their plausible rotational signatures, but with the same result, no rotational transitions could be found.

A similar search was carried out for Ca to observe the $N=1-0$, 2-1, and 3-2 transitions for CaCCCN predicted around 1.9, 3.8, and $5.7 \mathrm{GHz}$, respectively. No lines for this species or for any other higher energy isomers were found.

\section{DISCUSSION}

A reasonable agreement between the experimental and theoretically predicted spectroscopic parameters is generally observed in Table III. In the case of LiCCCN, the predicted rotational constant is within $2.3 \mathrm{MHz}$ of the experimental value. This remarkable agreement slightly deteriorates when moving to NaCCCN, with a discrepancy of around $22 \mathrm{MHz}$. It should be noted that the trend in the centrifugal distortion constants is well reproduced by theory in both cases. The electronic nuclear quadrupole coupling constants for the ${ }^{14} \mathrm{~N}$ nucleus in LiCCCN and NaCCCN agree well with the predicted values. The $\mathrm{LiCCCN}$ and $\mathrm{NaCCCN}$ determined $e Q q$ constants are very similar, -3.9695 (4) $\mathrm{MHz}$ and -3.8761 (5) $\mathrm{MHz}$, respectively, indicating that the electronic environment around the ${ }^{14} \mathrm{~N}$ nucleus is very similar in both species. On the other hand, the Li and $\mathrm{Na} e Q q$ values are well described by our calculations and they are similar to those found experimentally for analogous molecules, such as lithium and sodium acetylides. ${ }^{43}$ Thus, the $e Q q$ values for $\mathrm{Li}$ and $\mathrm{Na}$ in the $\mathrm{LiCCH}$ and $\mathrm{NaCCH}$ systems, $0.375 \mathrm{MHz}$ and $-7.264 \mathrm{MHz}$, respectively, ${ }^{43}$ are very close to our values of 0.3603 and $-7.0497 \mathrm{MHz}$, respectively. Thus, $\mathrm{Li}-\mathrm{C}$ and $\mathrm{Na}-\mathrm{C}$ bond characteristics in the LiCCCN and NaCCCN molecules are almost the same than those for $\mathrm{LiCCH}$ and $\mathrm{NaCCH}$, which present a high degree of ionic metalligand bonding character similar to the halides or hydroxides, while the covalent character of the metal-ligand bond is minimal, as it has been shown by Sheridan et al. ${ }^{43}$

Since we widely explored the predicted frequency regions for the rotational transitions for $\mathrm{MgCCCN}$ and $\mathrm{CaCCCN}$, we can conclude that the formation of both species does not take place using the current experimental conditions of laser ablation and the BrCCCN precursor. Different attempts were carried out using different experimental conditions with other laser wavelengths, focal distances, or laser fluencies as well as different precursors such as HCCCN and ICCCN, but all our trials resulted unfruitful. In fact, the production rates for LiCCCN and NaCCCN were very poor when HCCCN and ICCCN were employed instead of BrCCCN.

We wonder if $\mathrm{MgCCCN}$ and $\mathrm{CaCCCN}$ species have a very different behavior from LiCCCN and NaCCCN, in terms of their thermochemical properties. To get some insights, we calculated the reaction enthalpies for processes $\mathrm{M}+\operatorname{BrCCCN}(\mathrm{M}=\mathrm{Li}, \mathrm{Na}, \mathrm{K}, \mathrm{Cu}$, $\mathrm{Al}, \mathrm{Mg}$, and $\mathrm{Ca}$ ). We considered $\mathrm{Cu}$ and $\mathrm{Al}$ in addition to $\mathrm{Li}, \mathrm{Na}, \mathrm{Mg}$, and Ca because we previously investigated their gas phase generation and rotational spectra using the same method related to this work. For the reaction process $\mathrm{M}+\mathrm{BrCCCN} \rightarrow \mathrm{Br}+\mathrm{MCCCN}$, we found (see Table VII) that all the reaction enthalpies were negative except those for $\mathrm{Mg}$ and $\mathrm{Ca}$, which indicates that the formation of the $\mathrm{Mg}$ and Ca-cyanoacetylides is much less favorable than the formation of the analogs with $\mathrm{Li}, \mathrm{Na}, \mathrm{Al}$, or $\mathrm{Cu}$. In addition, we theoretically explored the thermochemistry on the formation of other species instead of the Mg- and CaCCCN and we found (at the B3LYP/augcc-pVTZ level of theory) that the production of symmetric species with the general formula NCCCMCCCN from MCCCN + CCCN is very favorable for $\mathrm{M}=\mathrm{Mg}$ and $\mathrm{Ca}$, with the formation enthalpies being -114.5 and $-52.14 \mathrm{kcal} / \mathrm{mol}$, respectively. These facts indicate that $\mathrm{Mg}, \mathrm{Ca}$, and $\mathrm{BrCCCN}$ can be involved in other reaction processes that preclude the formation of $\mathrm{MgCCCN}$ and $\mathrm{CaCCCN}$ in an enough proportion to be detected through rotational spectroscopy.

Finally, the rotational constants derived from the observed laboratory spectra of LiCCCN and NaCCCN allow performing a

TABLE VII. Reaction enthalpies ( $\mathrm{kcal} / \mathrm{mol}$ ) for the production of $\mathrm{MCCCN}$ species from $\mathrm{M}+\mathrm{BrCCCN}$. The level of calculation is $\operatorname{CCSD}(T) /$ aug-cc-pVTZ//MP2/aug-cc-pVTZ, including ZPE corrections at the MP2 level.

\begin{tabular}{lcccccr}
\hline \hline Reaction & $\mathrm{Li}$ & $\mathrm{Na}$ & $\mathrm{Mg}$ & $\mathrm{Ca}$ & $\mathrm{Al}$ & $\mathrm{Cu}$ \\
\hline $\mathrm{M}+\mathrm{BrCCCN} \rightarrow \mathrm{Br}+\mathrm{MCCCN}$ & -17.14 & -7.37 & 16.46 & 0.73 & -12.49 & -14.48 \\
\hline \hline
\end{tabular}


search in the millimeter domain using the $3 \mathrm{~mm}$ line survey of IRC +10216 taken with the 30-m IRAM (Institut de Radioastronomie Millimétrique) radio telescope. ${ }^{44,45}$ The values of the experimental constants obtained in the present investigation have been used to predict its transitions in the $3 \mathrm{~mm}$ domain with uncertainties of $0.15-0.4 \mathrm{MHz}$. We have searched for possible lines within $\pm 20 \mathrm{MHz}$ around the predicted frequencies which is enough to search for features with a total linewidth $\sim 29 \mathrm{~km} / \mathrm{s}$. Unfortunately, we have not detected plausible candidates for the transitions $J=27-26$ up to $J=44-43$. From the most sensitive spectra, and assuming that $\mathrm{NaCCCN}$ could arise from the same region as $\mathrm{NaCN},{ }^{46}$ we obtain an upper limit $(3 \sigma)$ to the column density of NaCCCN in front of IRC +10216 of $<8 \times 10^{10} \mathrm{~cm}^{-2}$. The upper limit obtained for the column density of $\mathrm{NaCCCN}$ is around 100 times lower than that for $\mathrm{NaCN}$. The chemical paths leading to the formation of $\mathrm{NaCN}$ and $\mathrm{NaCCCN}$ have been discussed previously by Petrie. ${ }^{47}$ The chemical models, performed by Cabezas et al. ${ }^{27}$ and Quintana-Lacaci et al. ${ }^{46}$ show that the main formation path for these species involves HCN, HCCCN, and $\mathrm{Na}$ ions. The derived abundance ratio $\mathrm{NaCN} / \mathrm{NaCCCN}$ is compatible with an abundance ratio $\mathrm{HCN} / \mathrm{HCCCN}>100$.

A similar search was done for LiCCCN and an upper limit similar to that for NaCCCN was obtained. The nonobservation is expected due to the probable low abundance of lithium in the ISM and the lack of emission from species such as $\mathrm{LiCl}, \mathrm{LiF}$, or $\mathrm{LiCN}$, which could be more abundant than LiCCCN.

\section{CONCLUSIONS}

The cyanoacetylides LiCCCN and NaCCCN have been synthesized and characterized in the laboratory using a combination of laser ablation techniques and Fourier transform microwave spectroscopy. This method is not suitable for MgCCCN and CaCCCN, which could not be detected using the same experimental procedure as that for LiCCCN and NaCCCN. Additionally, we have carried out high-level $a b$ initio quantum chemical calculations for $\mathrm{Li}, \mathrm{Na}$, $\mathrm{Mg}$, and Ca cyanoacetylides to investigate the geometries and stabilities of these molecules and to provide accurate rotational transition frequencies that allow their spectroscopic characterization. The analysis of the rotational spectra rendered the experimental rotational parameters that are in reasonable good agreement with those predicted theoretically.

The nonobservation of MgCCCN and $\mathrm{CaCCCN}$ has been interpreted in terms of a different thermochemical behavior of $\mathrm{Mg}$ and $\mathrm{Ca}$ with respect to that of $\mathrm{Li}$ and $\mathrm{Na}$. From our results, it seems that $\mathrm{Mg}$, $\mathrm{Ca}$, and BrCCCN can undergo different reaction processes under our experimental conditions.

\section{SUPPLEMENTARY MATERIAL}

See supplementary material for all the measured transition frequencies for LiCCCN and NaCCCN species.

\section{ACKNOWLEDGMENTS}

This research was supported by the European Research Council under the European Union's Seventh Framework Programme (FP/2007-2013)/ERC-2013-SyG (Grant Agreement No. 610256
NANOCOSMOS), by the Ministerio de Economía y Competitividad of Spain (Grant Nos. CTQ 2013-40717-P, CTQ 2013-76393-P, AYA2017-87515-P, and Consolider-Ingenio 2010 CSD2009-00038), and by the Junta de Castilla y León (Grant Nos. VA175U13, VA010G18, and VA077U13). J.C.G. is thankful to the Centre National d'Etudes Spatiales (CNES) and the Program PCMI (INSUCNRS) for financial support.

\section{REFERENCES}

${ }^{1}$ H. Umeki, M. Nakajima, and Y. Endo, J. Chem. Phys. 141, 184303 (2014).

${ }^{2}$ C. Cabezas, C. Barrientos, A. Largo, J.-C. Guillemin, J. Cernicharo, I. Peña, and J. L. Alonso, J. Chem. Phys. 141, 104305 (2014).

${ }^{3}$ C. Cabezas, C. Barrientos, A. Largo, J.-C. Guillemin, and J. L. Alonso, Phys. Chem. Chem. Phys. 18, 28538 (2016).

${ }^{4}$ D. B. Grotjahn, M. A. Brewster, and L. M. Ziurys, J. Am. Chem. Soc. 124, 5895 (2002).

${ }^{5}$ M. A. Brewster and L. M. Ziurys, J. Chem. Phys. 117, 4853 (2002).

${ }^{6}$ P. M. Sheridan and L. M. Ziurys, J. Chem. Phys. 118, 6370 (2003).

${ }^{7}$ P. M. Sheridan, M. A. Flory, and L. M. Ziurys, J. Chem. Phys. 121, 8360 (2004).

${ }^{8}$ M. A. Flory, R. W. Field, and L. M. Ziurys, Mol. Phys. 105, 585 (2007).

${ }^{9}$ C. T. Kingston, A. J. Merer, and T. D. Varberg, J. Mol. Spectrosc. 215, 106 (2002).

${ }^{10}$ O. Dietz, V. M. Rayón, and G. Frenking, Inorg. Chem. 42, 4977 (2003).

${ }^{11}$ V. M. Rayón, P. Redondo, H. Valdés, C. Barrientos, and A. Largo, J. Phys. Chem.

A 111, 6334 (2007).

${ }^{12}$ J. Lie and P. J. Dagdigian, J. Chem. Phys. 114, 2137 (2001).

${ }^{13}$ M. A. Flory and L. M. Ziurys, J. Chem. Phys. 135, 184303 (2011).

${ }^{14}$ L. N. Zack, J. Min, B. J. Harris, M. A. Flory, and L. M. Ziurys, Chem. Phys. Lett. 514, 202 (2011)

${ }^{15}$ K. Kawaguchi, E. Kagi, T. Hirano, S. Takano, and S. Saito, Astrophys. J. 406, L39 (1993).

${ }^{16}$ L. M. Ziurys, C. Savage, J. L. Highberger, A. J. Apponi, M. Guelin, and J. Cernicharo, Astrophys. J. 564, L45 (2002).

${ }^{17}$ M. Guelin, S. Müller, J. Cernicharo, A. J. Apponi, M. C. McCarthy, C. A. Gottlieb, and P. Thaddeus, Astron. Astrophys. 363, L9 (2000).

${ }^{18}$ T. Hirano, K. Ishii, T. E. Odaka, and P. Jensen, J. Mol. Spectosc. 215, 42 (2002).

${ }^{19}$ M. L. Senent, F. Dumouchel, and F. Lique, Mon. Not. R. Astron. Soc. 420, 1188 (2012).

${ }^{20}$ E. Clementi, H. Kistenmacher, and H. Popkie, J. Chem. Phys. 58, 2460 (1973).

${ }^{21}$ C. J. Marsden, J. Chem. Phys. 76, 6451 (1982).

${ }^{22}$ T. Törring, J. P. Bekooy, W. Leo Meerts, J. Hoeft, E. Tiemann, and A. Dymanus, J. Chem. Phys. 73, 4875 (1980).

${ }^{23}$ J. J. van Vaals, W. L. Meerts, and A. Dymanus, Chem. Phys. 86, 147 (1984).

${ }^{24}$ B. E. Turner, T. C. Steimle, and L. Meerts, Astrophys. J. 426, L97 (1994).

${ }^{25}$ R. L. Pulliam, C. Savage, M. Agúndez, J. Cernicharo, M. Guélin, and L. M. Ziurys, Astrophys. J. 725, L181 (2010).

${ }^{26}$ L. M. Ziurys, A. J. Apponi, M. Guélin, and J. Cernicharo, Astrophys. J. 445, L47 (1995).

${ }^{27}$ C. Cabezas, J. Cernicharo, J. L. Alonso, M. Agúndez, S. Mata, M. Guelin, and I. Peña, Astrophys. J. 775, 133 (2013).

${ }^{28}$ M. Guélin, S. Muller, J. Cernicharo, M. C. McCarthy, and P. Thaddeus, Astron. Astrophys. 426, L49 (2004).

${ }^{29}$ L. N. Zack, D. T. Halfen, and L. M. Ziurys, Astrophys. J. 733, L36 (2011).

${ }^{30} \mathrm{G}$. Winnewisser and C. M. Walmsley, Astron. Astrophys. 70, L37 (1978).

${ }^{31}$ T. H. Dunning, J. Chem. Phys. 90, 1007 (1989).

${ }^{32}$ J. Koput and K. A. Peterson, J. Phys. Chem. A 106, 9595 (2002).

${ }^{33}$ K. Raghavachari, G. W. Trucks, J. A. Pople, and M. A. Head-Gordon, Chem. Phys. Lett. 157, 479 (1989).

${ }^{34}$ M. Heckert, M. Kalay, and J. Gauss, Mol. Phys. 103, 2109 (2005).

${ }^{35}$ M. Heckert, M. Kalay, D. P. Tew, W. Klopper, and J. Gauss, J. Chem. Phys. 125, 044108 (2006). 
${ }^{36}$ V. Barone, M. Biczysko, J. Bloino, and C. Puzzarini, J. Chem. Theory Comput. 9, $1533(2013)$

${ }^{37}$ M. J. Frisch, G. W. Trucks, H. B. Schlegel, G. E. Scuseria, M. A. Robb, J. R. Cheeseman, G. Scalmani, V. Barone, B. Mennucci, G. A. Petersson, H. Nakatsuji, M. Caricato, X. Li, H. P. Hratchian, A. F. Izmaylov, J. Bloino, G. Zheng, J. L. Sonnenberg, M. Hada, M. Ehara, K. Toyota, R. Fukuda, J. Hasegawa, M. Ishida, T. Nakajima, Y. Honda, O. Kitao, H. Nakai, T. Vreven, J. A. Montgomery, Jr., J. E. Peralta, F. Ogliaro, M. Bearpark, J. J. Heyd, E. Brothers, K. N. Kudin, V. N. Staroverov, T. Keith, R. Kobayashi, J. Normand, K. Raghavachari, A. Rendell, J. C. Burant, S. S. Iyengar, J. Tomasi, M. Cossi, N. Rega, J. M. Millam, M. Klene, J. E. Knox, J. B. Cross, V. Bakken, C. Adamo, J. Jaramillo, R. Gomperts, R. E. Stratmann, O. Yazyev, A. J. Austin, R. Cammi, C. Pomelli, J. W. Ochterski, R. L. Martin, K. Morokuma, V. G. Zakrzewski, G. A. Voth, P. Salvador, J. J. Dannenberg, S. Dapprich, A. D. Daniels, O. Farkas, J. B. Foresman, J. V. Ortiz, J. Cioslowski, and D. J. Fox, GAUSSIAN 09, Revision B.01, Gaussian, Inc., Wallingford, CT, 2010.

${ }^{38}$ J. F. Stanton, J. Gauss, M. E. Harding, and P. G. Szalay, CFOUR, a quantum chemical program package, 2013
${ }^{39}$ C. Bermúdez, S. Mata, C. Cabezas, and J. L. Alonso, Angew. Chem., Int. Ed. 53, 11015 (2014)

${ }^{40}$ T. J. Balle and W. H. Flygare, Rev. Sci. Instrum. 52, 33 (1981).

${ }^{41}$ H. M. Pickett, J. Mol. Spectrosc. 148, 371 (1991).

${ }^{42}$ W. Gordy and R. L. Cook, Microwave Molecular Spectra, 3rd ed. (Wiley, New York, 1984).

${ }^{43}$ P. M. Sheridan, M. K. L. Binns, M. Sun, J. Min, M. P. Bucchino, D. T. Halfen, and L. M. Ziurys, J. Mol. Spectrosc. 269, 231 (2011).

${ }^{44}$ J. Cernicharo, M. Guélin, M. Agúndez, M. C. McCarthy, and P. Thaddeus, Astrophys. J. 688, L83 (2008).

${ }^{45}$ Cernicharo et al., "A sensitive line survey at $3 \mathrm{~mm}$ with the $30 \mathrm{~m}$ IRAM radio telescope of IRC+10216" (unpublished).

${ }^{46}$ G. Quintana-Lacaci, J. Cernicharo, L. Velilla Prieto, M. Agúndez, A. CastroCarrizo, J. P. Fonfría, S. Massalkhi, and J. R. Pardo Astron. Astrophys. 607, L5 (2017).

${ }^{47}$ S. Petrie, Mon. Not. R. Astron. Soc. 302, 482 (1999). 